\title{
ЭКСПЕРИМЕНТАЛЬНАЯ ГИДРОБИОЛОГИЯ
}

УДК 581.526.325:581.14(262.5)

\section{СТРУКТУРНО-ФУНКЦИОНАЛЬНЫЕ ВЗАИМОСВЯЗИ ПОПУЛЯЦИЙ В ПЛАНКТОННОМ СООБЩЕСТВЕ * Чмыр В.Д., Ли Р.И. \\ ФГБУН ФИЦ «Институт биологии южных морей имени А.О. Ковалевского РАН», \\ 2. Севастополь, Российская Федераиия, e-mail:vchmyr35@mail.ru, raisa-lee@yandex.ru}

Метод разбавления позволяет определять скорость роста и выедания суммарного фитопланктона, биомасса которого оценивается по концентрации хлорофилла а. В апреле - мае 2017 г. нами проведены эксперименты, в ходе которых была разработана модификация метода разбавления с целью определения основных функциональных параметров популяций отдельных видов фитопланктона. В задачи эксперимента входило определение соотношения скорости видимого и действительного роста с тем, чтобы оценивать значения скорости действительного роста и выедания по результатам короткопериодного мониторинга численности фитопланктона in situ. Однако, полученные в ходе экспериментов результаты не только выходят за рамки заявленных целей, но и позволяют выйти на новый уровень комплексных исследований планктонного сообщества, возможность которых и рассматривается в настоящей публикации. Так, полученные зависимости скорости роста и выедания от размера клеток показывают, что все функциональные параметры фитопланктона, в принципе, могут быть рассчитаны непосредственно по структурным характеристикам.

Ключевые слова: фитопланктон, сообщество, популяция; структура, скорость роста, элиминация.

\section{Введение}

Применяемый для изучения первичной продукции водоёмов метод склянок, как в кислородном (Винберг, 1934), так и в радиоуглеродном (Steemann Nielsen, 1952) вариантах позволяет определять суммарную продукцию фитопланктона. Определения скорости роста отдельных видов фитопланктона в условиях естественного сообщества впервые были проведены Т.М. Кондратьевой в 1961 г. в стеклянных цилиндрах, торцы которых были затянуты пористыми мембранами (Кондратьева, 1961). По этой методике позже проводили определения на Байкале (Антипова, Загоренко, 1971) и в бухте Севастопольская (Сеничева, 1980), которые позволили успешно рассчитывать как продукцию отдельных видов, так и первичную продукцию всего фитоцена. Однако, в дальнейшем метод Кондратьевой, требующий трудоёмкого анализа проб под микроскопом, игнорировали, как устаревший, а определения первичной продукции, особенно в морских акваториях, проводили преимущественно радиоуглеродным методом.

Предложенный несколько позже метод разбавления (Landry et al., 1982, 1984) позволяет определять скорость роста и выедания всего фитоцена, биомасса которого оценивается по концентрации хлорофилла а. В апреле - мае 2017 г. проведены

\footnotetext{
* Работа выполнена в рамках госзадания ФИЦ ИнБЮМ по теме «Функииональные, метаболические и токсилогические аспекты существования гидробионтов и их популящий в биотопах с различным физико-химическим режимом (гос. рег. № AAAA-A18-118021490093-4).
} 
эксперименты, в ходе которых была разработана модификация метода разбавления, позволившая впервые определить основные функциональные параметры популяций отдельных видов. Предполагалось использовать результаты эксперимента для оценки функциональных параметров популяций по значениям скорости видимого роста, определяемого в результате подекадного мониторинга их численности (Чмыр, Ли, 2019). Однако полученные в ходе этих экспериментов результаты выходят за рамки заявленных ранее целей и позволяют выйти на новый уровень комплексных исследований планктонного сообщества, возможность которых и рассматривается в настоящей публикации.

Для ясности изложения приводим основные методические положения нашей модификации метода разбавления.

\section{Материалы и методы}

Метод разбавления был предложен в 1982 г. М. Landry с соавторами (Landry and Hassett, 1982; Landry et al., 1984) и получил широкое распространение для определения интегральных значений скорости роста и выедания суммарного фитопланктона в природных сообществах. К настоящему времени создана литература, насчитывающая сотни публикаций, описывающих результаты этих исследований. В нашей работе теоретические построения, терминология и уравнения расчётов соответствуют в основном изложенным в работах авторов метода разбавления (Landry and Hassett, 1982; Landry et al., 1984; Landry et al., 2008; Li et al., 2010). Конкретные буквенные обозначения в уравнениях, как правило, соответствуют первоисточникам. Минимальные замены предприняты с целью унификации обозначений в настоящем изложении.

Метод разбавления основан на сопоставлении плотности фитопланктона в начале $\left(\boldsymbol{p}_{0}\right)$ и в конце $\left(\boldsymbol{p}_{t}\right)$ экспозиции цельных и разбавленных фильтрованной водой проб в условиях близких к естественным. Принимается, что за время экспозиции концентрация питательных веществ и скорость размножения клеток остаётся постоянной, а скорость выедания изменяется пропорционально изменяющейся при разбавлении концентрации консументов. Основными потребителями фитопланктона являются организмы микрозоопланктона - преимущественно инфузории и личинки ракообразных размером от 20 до 200 мкм. Суммарную плотность фитопланктона первоначально оценивали по концентрации хлорофилла а.

В наших экспериментах классический метод разбавления, предназначенный для исследования суммарного фитопланктона, мы адаптировали для определения функциональных параметров отдельных видов. Для этого находили коэффициенты видимого роста за время экспозиции $(\boldsymbol{t}$, сут) численности клеток $(\boldsymbol{n})$ каждого исследуемого вида отдельно в цельной $(\boldsymbol{k})$ и в разбавленной $\left(\boldsymbol{k}_{\boldsymbol{d}}\right)$ пробах по следующим уравнениям:

$$
\begin{aligned}
& k-\ln \left(\frac{n_{t}}{n_{0}}\right) / \Delta t, \\
& k_{d}=\ln \left(\frac{n_{t} d}{n_{0} d}\right) / \Delta t,
\end{aligned}
$$

Используя значения коэффициентов $\boldsymbol{k}$ и $\boldsymbol{k}_{\boldsymbol{d}}$, находили коэффициент элиминации $\boldsymbol{m}$ :

$$
m=\frac{k_{d}-k}{1-x}
$$

где $\boldsymbol{x}$ - доля цельной воды в составе разбавленной пробы, объём которой принят равным единице. 
Скорость размножения (действительный рост, $\boldsymbol{\mu}$ ) принимается как сумма видимого роста и элиминации:

$$
\mu=k+m
$$

Единицей измерения значений $\boldsymbol{k}, \boldsymbol{m}$ и $\boldsymbol{\mu}$ является $\mathbf{c y т}^{-1}$.

Зная начальную биомассу $\boldsymbol{B}_{\mathbf{0}}$, по найденным значениям $\boldsymbol{m}$ и $\boldsymbol{\mu}$ можно рассчитать значения продукции $\boldsymbol{P}$ и выедания $\boldsymbol{G}$ популяции каждого вида в мг $^{*} \mathrm{M}^{3 *}$ сут $^{-1}$ :

$$
\begin{aligned}
& P=\mu \times B_{0}\left(e^{(\mu-m) t}-1\right) /(\mu-m), \\
& G=m \times B_{0}\left(e^{(\mu-m) t}-1\right) /(\mu-m),
\end{aligned}
$$

Для проведения экспериментов воду отбирали с поверхности моря на станции Равелин, расположенной в фарватере Севастопольской бухты вблизи её устья. Воду наливали в 5-литровые пластиковые баллоны.

В одной ёмкости проба на две трети объёма была разбавлена водой, пропущенной через ядерный фильтр (диаметр ячеи 1 мкм). В другой ёмкости проба оставалась неразбавленной. Баллоны экспонировали в море у причала экспериментального корпуса института в течение трёх суток. В начале и в конце экспозиции определяли численность клеток каждого найденного вида в обеих экспериментальных ёмкостях. Для определения фитопланктона пробы объемом до 2 л концентрировали на воронке обратной фильтрации, оборудованной фильтром с диаметром ячеи 1 мкм (Сорокин, 1979, Суханова, 1983) до объёма 10 мл и фиксировали 1 мл нейтрализованного 40\% формалина. Подсчет клеток фитопланктона различной плотности и размерного состава осуществляли под световым микроскопом ЛОМО Микмед-2 (увеличением крат 40x $1500 x$. Расчет объема и биомассы клеток проводили по стандартным методикам (Киселев, 1956), Водоросли. Справочник, 1989).

\section{Результаты и обсуждение}

Чтобы по полученным в естественной популяции значениям скорости видимого роста оценить скорость действительного роста и выедания, необходимо было установить взаимосвязь между этими показателями. С этой целью в апреле - мае 2017 г. были проведены эксперименты, в ходе которых в пробах, отобранных в устье Севастопольской бухты на станции Равелин, впервые были измерены функциональные параметры отдельных видов фитопланктона. Всего в этих пробах идентифицировано около 40 видов, хотя численность только 31 вида была существенной (табл. 1).

Таблица 1.

Численность видов фитопланктона (клеток/литр), обнаруженных 28 апреля 2017 г. в устье Севастопольской бухты на ст. (Равелин)

\begin{tabular}{|c|l|c|}
\hline $\begin{array}{c}\text { № } \\
\Pi / \Pi\end{array}$ & \multicolumn{1}{|c|}{ Таксон } & Клеток/литр \\
\hline \multicolumn{1}{|c|}{ ОТДЕЛ BACILLARIOPHYTA } \\
\hline 1 & \multicolumn{1}{|c|}{ Berkeleya micans (Lyngbye) Grunov 1868 } & 319 \\
\hline 2 & Chaetoceros affinis Lauder 1864 & 16907 \\
\hline 3 & Ch. coronatus Gran 1897 & 2233 \\
\hline 4 & Ch. curvisetus Cleve 1889 & 42746 \\
\hline 5 & Ch. insignis Proschkina-Lavrenko 1955 & 87406 \\
\hline 6 & Ch. peruvianus Brightwell 1856 & 2233 \\
\hline 7 & Ch. socialis H.S. Lauder 1864 & 69542 \\
\hline
\end{tabular}




\begin{tabular}{|c|c|c|}
\hline $\begin{array}{c}\text { № } \\
\text { П/П }\end{array}$ & Таксон & Клеток/литр \\
\hline 8 & Ch. subtilis Cleve 1896 & 34452 \\
\hline 9 & Cyclotella caspia Grunow 1878 & 1595 \\
\hline 10 & Diploneis sp. & 638 \\
\hline 11 & Licmophora abbreviata C.A. Agardh 1831 & 319 \\
\hline 12 & Fallacia forcipata (Greville) Stickle \& D.G. Mann in Round, Grawford \& Mann 1990 & 319 \\
\hline 13 & Navicula sp. & 319 \\
\hline 14 & Nitzshia tenuirostris Mereschk. 1902 & 14993 \\
\hline 15 & Pleurosigma elongatum W. Smith 1852 & 319 \\
\hline 16 & Pseudo-nitzschia delicatissima (Cleve) Heiden in Heiden et Kolbe 1928 & 2233 \\
\hline 17 & Dactyliosolen fragilissimus (Bergon) Hasle in Hasle \& Syvertsen 1996 & 1595 \\
\hline 18 & Skeletonema costatum (Greville) Cleve 1873 & 765600 \\
\hline \multicolumn{3}{|c|}{ ОТДЕЛ МIOZOA } \\
\hline 19 & Diplopsalis pilula Ostenfeld 1908 & 319 \\
\hline 20 & Gonyaulax spinifera Claparède \& Lachmann Diesing 1866 & 319 \\
\hline 21 & Heterocapsa triquetra (Ehrenberg) Stein 1883 & 2871 \\
\hline 22 & Prorocentrum micans Ehrenberg 1834 & 957 \\
\hline 23 & Protoceratium reticulatum (Claparède \& Lachmann) Bütschli 1885 & 638 \\
\hline 24 & Protoperidinium bipes (Paulsen) Balech 1974 & 1914 \\
\hline 25 & Protoperiedinium brevipes (Paulsen) Balech 1974 & 1276 \\
\hline 26 & Protoperidinium pallidum (Ostenfeld) Balech 1973 & 638 \\
\hline 27 & Protoperidinium pellucidum Bergh 1881 & 1914 \\
\hline 28 & Scrippsiella trochoidea (Stein) Loeblich III 1976 & 2233 \\
\hline \multicolumn{3}{|c|}{ ОТДЕЛ ОСНRОРНҮТА } \\
\hline 29 & Dinobryon porrectum Schiller 1925 & 319 \\
\hline \multicolumn{3}{|c|}{ ОТДЕЛ EUKARYOTA UNASSIGNED PHYLUM } \\
\hline 30 & Poropila dubia J.Schiller 1925 & 1276 \\
\hline \multicolumn{3}{|c|}{ ОТДЕЛ EUGLENOPHYТA } \\
\hline 31 & Euglena acusformis J. Shiller 1925 & 1595 \\
\hline
\end{tabular}

Из них для расчётов функциональных параметров могли быть использованы только массовые виды, обнаруживаемые в эксперименте в достаточных количествах в конце экспозиции. Этим требованиям вполне соответствовали только шесть видов диатомовых водорослей. Функциональные параметры: удельные суточные значения скорости видимого $(\boldsymbol{k})$ и действительного $(\boldsymbol{\mu})$ роста и скорости выедания $(\boldsymbol{m})$, а также значения продукции и выедания $\left(\mathrm{M \Gamma}^{*} \mathrm{M}^{-3 *} \mathrm{cys}^{-1}\right)$ были получены в эксперименте для этих шести видов водорослей, объём клеток которых варьировал от 75 до 1413 мкм ${ }^{3}$ (табл. 2).

По результатам эксперимента были рассчитаны зависимости функциональных показателей $\boldsymbol{k}, \boldsymbol{m}$ и $\boldsymbol{\mu}$, а также их соотношений $\boldsymbol{k} / \boldsymbol{\mu}, \mathbf{m} / \boldsymbol{\mu}$ и $\boldsymbol{k} / \boldsymbol{m}$ от объёма клеток водорослей:

$$
\begin{aligned}
& k=0,0004 V+0,0874, R^{2}=0,9544 \\
& m=0,8581 e^{-0,002 V}, \quad R^{2}=0,7469 \\
& \mu=1,1935 V^{-0,087}, \quad R^{2}=0,1665 \\
& \frac{k}{\mu}=0,0006 V+0,1109, \quad R^{2}=0,9334 \\
& \frac{m}{\mu}=0,0006 V+0,8896, \quad R^{2}=0,9326 \\
& \frac{k}{m}=0,1438 e^{-0,0028 V}, R^{2}=0,8866
\end{aligned}
$$

Графически эти зависимости представлены на рисунках 1, 2 и 3. 
Таблица 2.

Структурные и функциональные параметры популяций шести массовых видов фитопланктона в устье б. Севастопольская.

Эксперимент 28 апреля - 02 мая 2017 г."

\begin{tabular}{|c|c|c|c|c|c|c|c|c|c|c|c|}
\hline Виды & $\begin{array}{c}\boldsymbol{V} \\
\text { мКм }^{3}\end{array}$ & $\begin{array}{c}\boldsymbol{n}, \\
\text { кл/л }\end{array}$ & $\begin{array}{c}\boldsymbol{B}_{\boldsymbol{0}}, \\
\mathrm{M \Gamma} / \mathrm{M}^{3}\end{array}$ & $\begin{array}{c}\boldsymbol{k}, \\
\text { cyT }^{-1}\end{array}$ & $\begin{array}{c}m, \\
\text { cyT }^{-1}\end{array}$ & $\begin{array}{c}\boldsymbol{\mu}, \\
\text { cyт }^{-1}\end{array}$ & $k / \mu$ & $\mathbf{m} / \boldsymbol{\mu}$ & $k / m$ & $\begin{array}{c}\boldsymbol{P}, \\
{\mathrm{M \Gamma} \cdot \mathrm{M}^{-3}}_{\mathrm{cyT}^{-1}}\end{array}$ & $\begin{array}{c}\boldsymbol{G}, \\
{\mathrm{M \Gamma} \cdot \mathrm{M}^{-3}} \mathrm{cyT}^{-1}\end{array}$ \\
\hline $\begin{array}{l}\text { Chaetoceros } \\
\text { socialis }\end{array}$ & 75 & 69542 & 5,216 & 0,157 & 0,876 & 1,033 & 0,152 & 0,848 & 0,179 & 5,873 & 4,948 \\
\hline $\begin{array}{l}\text { Chaetoceros } \\
\text { subtilis }\end{array}$ & 157 & 34452 & 5,409 & 0,100 & 0,449 & 0,549 & 0,180 & 0,818 & 0,223 & 3,123 & 2,554 \\
\hline $\begin{array}{l}\text { Chaetoceros } \\
\text { insignis }\end{array}$ & 314 & 87406 & 27,45 & 0,170 & 0,694 & 0,864 & 0,200 & 0,803 & 0,245 & 25,85 & 20,76 \\
\hline $\begin{array}{l}\text { Sceletonem } \\
\text { costatum }\end{array}$ & 417 & 765600 & 319,8 & 0,291 & 0,305 & 0,596 & 0,490 & 0,512 & 0,954 & 220,8 & 113,0 \\
\hline $\begin{array}{l}\text { Chaetoceros } \\
\text { curvisetus }\end{array}$ & 1041 & 42746 & 44,50 & 0,433 & 0,247 & 0,680 & 0,640 & 0,363 & 1,248 & 37,87 & 19,32 \\
\hline $\begin{array}{l}\text { Chaetoceros } \\
\text { peruvianus }\end{array}$ & 1413 & 2233 & 3,155 & 0,629 & 0,049 & 0,678 & 0,928 & 0,072 & 12,84 & 2,978 & 0,215 \\
\hline
\end{tabular}

${ }^{*} \boldsymbol{V}$ - объём клетки, мкм ${ }^{3}, \boldsymbol{n}$ - число клеток в литре, $\boldsymbol{k}$ - удельная скорость видимого роста, сут $^{-1}, \boldsymbol{m}-$ удельная скорость выедания, сут ${ }^{-1}, \boldsymbol{\mu}$ - удельная скорость действительного роста, сут ${ }^{-1}, \boldsymbol{P}-$ продукция, $\mathrm{M \Gamma}^{*} \mathrm{M}^{-3 *}$ сут $^{-1}, \boldsymbol{G}$ - выедание, мг* $\mathrm{M}^{-3 *}$ сут $^{-1}, \boldsymbol{k} / \boldsymbol{\mu}, \boldsymbol{k} / \boldsymbol{m}$ - отношение скорости видимого роста к скорости действительного роста и скорости выедания, $\boldsymbol{m} / \boldsymbol{\mu}$ - отношение скорости выедания к скорости действительного роста.

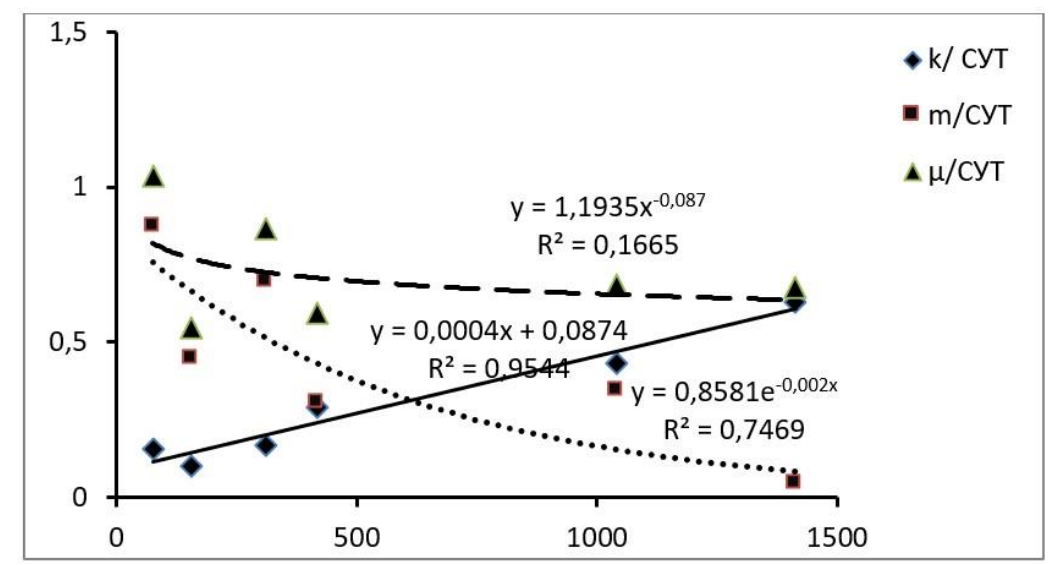

Рис. 1. Функции удельных значений скорости видимого $\left(\boldsymbol{k}^{*} \mathbf{c y \mathbf { T } ^ { - 1 } )}\right.$ и действительного $\left(\boldsymbol{\mu}^{*} \mathbf{c y s}^{-1}\right)$ роста, а также скорости выедания $\left(\boldsymbol{m}^{*} \mathbf{c y s}^{-1}\right)$ от объёма клеток водорослей $\left(\boldsymbol{V}, \mathbf{м \kappa м}^{3}\right)$. Эксперимент 28 апреля - 2 мая 2017 г., устье б. Севастопольская

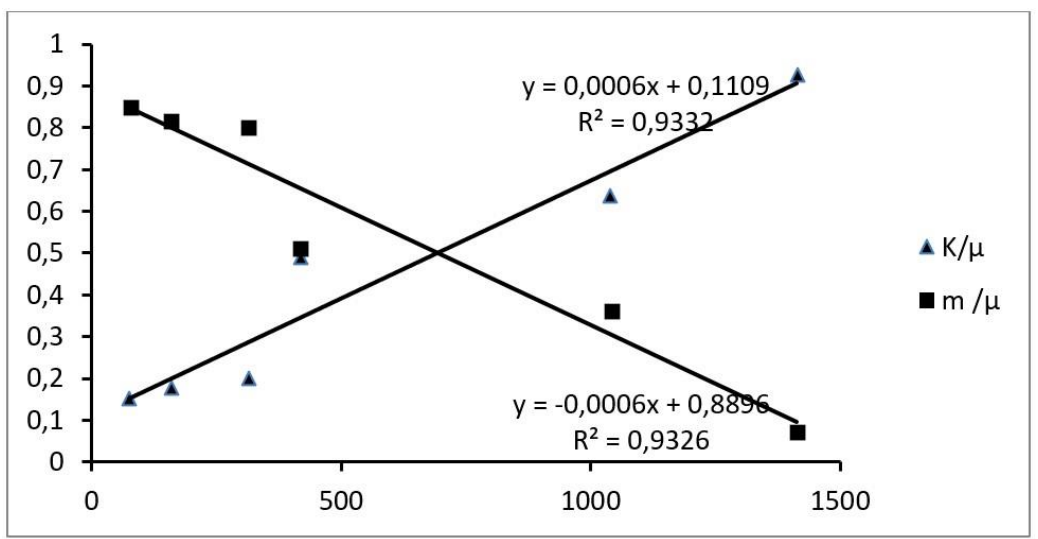

Рис. 2. Функции отношения удельных значений скоростей видимого и действительного роста $\boldsymbol{k} / \boldsymbol{\mu}$, а также скоростей выедания и действительного роста $\boldsymbol{m} / \boldsymbol{\mu}$ от объёма клеток водорослей $\boldsymbol{V}$, мкм $^{3}$ 


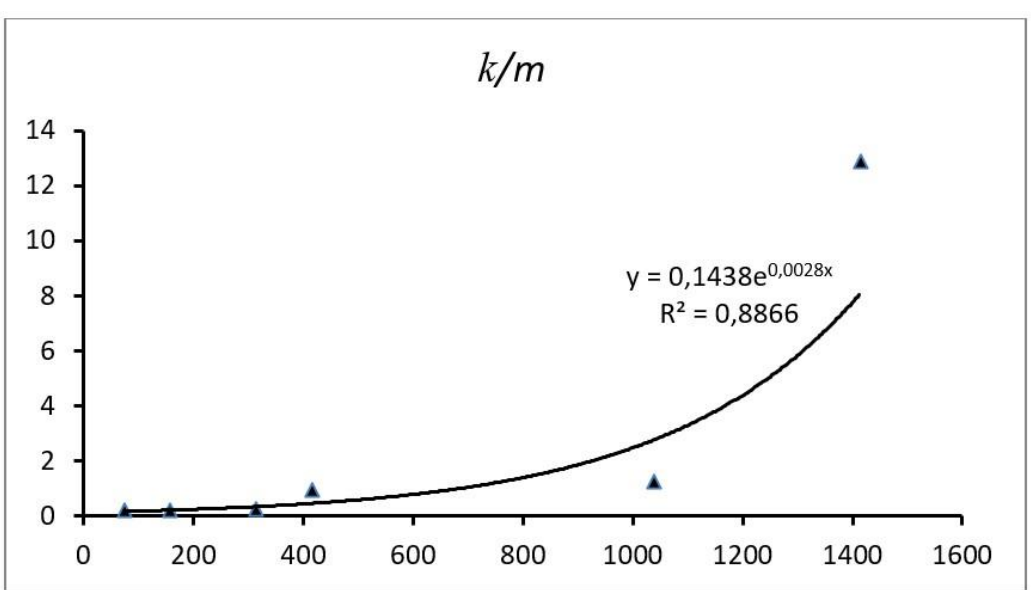

Рис. 3. Функция отношения удельных значений скорости видимого роста и скорости выедания $\boldsymbol{k} / \boldsymbol{m}$ от объёма клеток водорослей $\boldsymbol{V}$, мкм ${ }^{3}$

Согласно графикам, самый высокий коэффициент детерминации имеет зависимость скорости видимого роста $\boldsymbol{k}$ от объёма клетки $\left(\boldsymbol{R}^{2}=0,9544\right)$. Это связано с тем, что $\boldsymbol{k}$ измеряется непосредственно в неразбавленном варианте эксперимента, в то время как скорость выедания $\boldsymbol{m}\left(\boldsymbol{R}^{2}=0,7469\right)$ рассчитывается по результатам сопоставления данных, полученных также и при разбавлении. Наименьший коэффициент детерминации имеет зависимость скорости действительного роста $\boldsymbol{\mu}$ от объёма клетки $\left(\boldsymbol{R}^{2}=0,1665\right)$. Возможно, это объясняется тем, что $\boldsymbol{\mu}$ определяется как сумма $\boldsymbol{k}+\boldsymbol{m}$. Впрочем, все зависимости соотношений функциональных параметров от объёма клеток имеют высокие коэффициенты детерминации $\boldsymbol{R}^{2}-$ от 0,89 до 0,93.

Минимальные значения скорости видимого роста (около 0,1/сут) получены для самых мелких водорослей, которые имеют самые высокие скорости выедания и действительного роста (около 0,8/сут). По мере возрастания размера клеток до 1500 мкм значения скорости выедания стремятся к нулю, а видимой и действительной скорости роста - к одинаковым значениям (около $0,65 /$ сут).

В задачи экспериментов первоначально входило определение соотношения скоростей видимого и действительного роста с тем, чтобы использовать полученные соотношения для оценки скорости действительного роста и выедания популяций отдельных видов по результатам короткопериодного мониторинга их численности в природных сообществах. Однако полученные зависимости свидетельствуют о взаимосвязи структурных и функциональных параметров популяций в планктонном сообществе: трофическая роль популяций в сообществе определяется размерами их клеток, более крупные организмы микрозоопланктона потребляют фитопланктон в соответствии с его структурными характеристиками. Эти классические представления о характере трофических связей получили выражение в виде уравнений.

\section{Выводы}

Если рассматривать найденные в экспериментах зависимости, как свойственные всем подобным планктонным сообществам в сходных условиях, полученные уравнения с высокими значениями коэффициентов детерминации, с учётом соответствующих температурных и других поправок, в принципе, могут быть использованы для определения функциональных параметров других подобных популяций непосредственно по размерам их клеток, т.е. для конкретных расчётов скорости роста, продукции и потребления по результатам обычного таксономического анализа фитопланктона. 
Приведенные зависимости получены для популяций шести видов диатомовых. Поскольку максимальные скорости роста диатомовых в два-три раза выше, чем у представителей динофитовых - другой наиболее распространённой таксономической группы одноклеточных водорослей (Стельмах, Мансурова, 2017) - очевидна необходимость проведения аналогичных исследований как для этой, так и для других таксономических групп водорослей, чтобы получить полную картину структурнофункционального взаимодействия популяций в планктонном сообществе.

\section{Список литературы}

1. Антипова Н.Л., Загоренко Г.Ф. К вопросу об определении суточной продукции некоторых видов Байкальского фитопланктона. - Изв. Биол.-геогр. НИИ при Иркут. ун-те. 1971. 25. С. 20-29.

2. Винберг Г.Г. Опыт изучения фотосинтеза и дыхания в водной массе озера. К вопросу о балансе органического вещества. - Сообщ. 1. Тр. Лимнол. ст. в Косине. 1934. 18. С. 5-24

3. Киселев И.А. Методы исследования планктона // Жизнь пресных вод СССР. Ленинград: АН СССР, 1956. Т. 4. С. 183-270.

4. Кондратьева T.M. Определение суточной продукции фитопланктона в Севастопольской бухте. - В кн.: Первичная продукция морей и внутренних вод. Минск: Мин. Высш. и средн. спец. образования БССР, 1961. С. $71-82$.

5. Сеничева М.И. Сезонная динамика численности, биомассы и продукции фитопланктона Севастопольской бухты // Экология моря. 1980. Вып. 1. С. 3-11.

6. Сорокин Ю.И. К методике концентрирования проб фитопланктона // Гидробиологический журнал. 1979. Т. 15. С. 71-76

7. Стельмах Л.В., Мансурова И.М. Унимодальная зависимость скорости роста от объёма клеток в культурах черноморских видов микроводорослей // Вопросы современной альгологии. 2017 № 1 (13). [Электронный ресерс]. Режим доступа: http://algology.ru/1101.

8. Суханова И.Н. Концентрирование фитопланктона в пробе // Современные методы количественной оценки распределения морского планктона. - М.: Наука, 1983. С. 97 105

9. Водоросли. Справочник / Вассер С.П., Кондратьева Н.В., Масюк Н.П. и др. - Киев: Наук. думка, 1989. 608 с.

10. Чмыр В.Д., Ли Р.И., Сеничева М.И. Определение скорости роста и элиминации отдельных видов и популяций в сообществе фитопланктона бухты Севастопольская (Чёрное море) // Морской биологический журнал. 2019. Том 4 № 3. С. 81-94.

11. Landry M.R. Hassett R.P. Estimating the grazing impact of marine micro - zooplankton // Marine Biology. 1982. 67. P. 283-288.

12. Landry M.R., Haas L.W., Fagerness V.L. Dynamics of microplankton communities: experiments in Kaneohe Bay, Hawaii // Marine Ecology Progress Series. 1984. № 16. P. 127-133.

13. Landry M.R., Brown S.L. et al. Depth-stratified phytoplankton dynamics in Cyclone Opal, a subtropical mesoscale eddy // Deep-See Res., 2008. II, № 55. P. 1348-1359.

14. Li Q.P., Franks P.J.S., Landry M.R., Goericke R., Taylor A.G. Modeling phytoplankton growth rates and chlorophyll to carbon ratios in California coastal and pelagic ecosystems // J. Geophys. Res. 2010. № 115. G04003, doi: 10.1029/2009 JG001111.

15. Steemann Nielsen $E$. The use of radio-active carbon $\left(\mathrm{C}^{14}\right)$ for measuring organic production in the sea // J. Conseil perman. Internat. Explorat. Mer. 1952. № 18. P. 117-140. 


\section{STRUCTURAL AND FUNCTIONAL RELATIONSHIPS OF POPULATIONS IN THE PLANKTON COMMUNITY \\ Tchmyr V.D., Lee R.I.}

A.O. Kovalevsky Institute of Biology of the Southern Seas of RAS, Sevastopol, Russian Federation, e-mail: vchmyr35@mail.ru, raisa-lee@yandex.ru

The dilution method allows you to determine the growth rate and consumption of total phytoplankton, whose biomass is estimated by the concentration of chlorophyll "a". In April - May 2017, we conducted experiments, during which a modification of the dilution method was developed in order to determine the main functional parameters of the populations of individual phytoplankton species. The objectives of the experiment included assessing the ratio of the rate of apparent and actual growth in order to evaluate the values of the rate of actual growth and grazing out from the results of short-period monitoring of the phytoplankton abundance "in situ". However, the results obtained during the experiments not only go beyond the stated goals, but also allow to reach a new level of comprehensive research of the plankton community, the possibility of which is considered in this publication. Thus, the obtained dependences of the growth and grazing rates on the cell size show that, in principle, all the functional parameters of phytoplankton can be calculated directly from the structural characteristics.

Keywords: phytoplankton, community, population, growth rate, elimination, structure.

$\begin{array}{ll}\text { Чмыр } & \text { Кандидат биологических наук, старший научный сотрудник отдела } \\ \text { Виктор } & \text { функцинирования морских экосистем, ФГБУН ФИЦ «Институт } \\ \text { Демьянович } & \text { биологии южных морей имени А.О. Ковалевского РАН, } \\ & \text { e-mail: } \underline{\text { vchmyr35@ mail.ru }}\end{array}$

Ли Научный сотрудник отдела функционирования морских экосистем,

Раиса ФГБУН ФИЦ «Институт биологии южных морей имени Игнатьевна А.О. Ковалевского РАН, e-mail: raisa-lee@yandex.ru 